\title{
The locative syntax of Experiencers. The case study of phraseological units as psych-predicates
}

\author{
Anna Dąbrowska \\ John Paul II Catholic University of Lublin, Poland
}

\begin{abstract}
The name psych-verbs is commonly assigned to verbs denoting mental or emotional states, such as fear, worry, frighten, or surprise. Such verbs select a participant/an individual who experiences an emotional or mental state, usually referred to as an Experiencer, and a non-Experiencer argument, sometimes called stimulus, trigger of emotion, causer or target/subject matter, or subsumed under the label of 'theme' (Landau, 2010, p. 5). The special behaviour of Experiencers, related to the so-called 'psych effects', is the reason why psychological predicates have been a subject of debate in theoretical syntax for several decades.

The aim of this study is to check whether English verbal phraseological units, which denote a psychological condition of an Experiencer and occur with locative Prepositional Phrases (PPs), may serve as evidence for Landau's (2010, p. 6) hypothesis of 'Experiencers as mental locations'. Landau's theory has been chosen since it covers a much broader variety of data, in comparison with the previous approaches, offered by Belletti \& Rizzi (1988), Grimshaw (1990), and Pesetsky (1995), among others.

The data analysed in the paper have been extracted from English dictionaries of idiomatic expressions, supported with the COCA Corpus. The study focuses on Object Experiencer verbal phraseological units that display a structure V + PP. The results of the study reveal that, in total, out of 3,000 tokens, there are only 50 psychological verbal idiomatic expressions with an Object Experiencer. However, the data show that a lexical $\mathrm{P}$ with the Experiencer as an object appears only in $13(26 \%)$ idiomatic expressions out of the 50, whereas 37 items (74\%) include an Experiencer preceded with no P. The latter might be treated as exhibiting an oblique Experiencer with a null preposition. However, no relevant syntactic evidence can be found in support the claim that there is a covert $\mathrm{P}$ in this type of phrase. Therefore, the results do not provide enough evidence in favour of Landau's (2010) theory of Experiencers as mental locations, placed either in a covert or overt PP.
\end{abstract}

Keywords: psych-verbs, Experiencers, mental locations, verbal idioms

\section{Introduction}

The name psych-verbs is commonly assigned to verbs denoting mental or emotional states, such as fear, love, worry, frighten, or surprise. Such verbs select a participant/an individual who experiences an emotional or mental state, usually referred to as an Experiencer. The nonExperiencer argument, in turn, is sometimes called stimulus, trigger of emotion, causer or 
target/subject matter, or simply subsumed under the label of 'theme' (Landau, 2010, p. 5). The special behaviour of Experiencers, related to the so-called 'psych effects', is the reason why psychological predicates have been a subject of debate in theoretical syntax for several decades.

The aim of this paper is to check whether English verbal phraseological units, which denote a psychological condition of an Experiencer and occur with locative Prepositional Phrases (PPs), may serve as evidence for Landau's (2010, p. 6) hypothesis of 'Experiencers as mental locations, that is, locative'. Therefore, the paper is set in the theoretical framework of Landau (2010). In his monograph, The Locative Syntax of Experiencers (2010), Landau offers a comprehensive theory of the syntax of psych-verbs. Not only does Landau link Experiencers with locatives, which has never been recognised before, but he also combines various ideas into a coherent proposal in which Experiencers are viewed as mental locations, i.e. as locative Prepositional Phrases (PPs) undergoing locative inversion (LI), either overtly or covertly, depending on the language. Landau's theory also covers a much broader variety of data, in comparison with the previous approaches, offered by Belletti \& Rizzi (1988), Grimshaw (1990), and Pesetsky (1995), among others.

In the article, which comprises four sections, the following part, section 2, provides a classification of psych-verbs offered in the literature. It also presents the key distinction between Subject Experiencer and Object Experiencer psych-verbs, with a special focus on Object Experiencer (ObjExp) psych-verbs, which, in contrast to Subject Experiencer (SubjExp) psychverbs, are syntactically more complex, exhibiting a number of seemingly conflicting properties (cf. Landau, 2010, p. 5). Besides, an overview of syntactic properties of English ObjExp psychverbs is offered, which is relevant for an analysis undertaken in the paper. The aim of the research part, in Section 3, is to find some equivalents of psych-verbs among the phraseological verbal idiomatic units that depict the mental/emotional condition of an Experiencer. An attempt is made to check whether it is justified to treat those phraseological items as periphrastic variants of psych-verbs with locative Prepositional Phrases (PPs). Finally, the paper ends with the summary, provided in section 4 .

\section{Classification and syntactic properties of psych-verbs}

\subsection{Defining and classifying psych-verbs}

The working definition of psych-verbs adopted for the purpose of our analysis is the one provided by Landau (2010, p. 4n2), who defines psychological verbs as those which carry "psychological entailments involving an individual being in a certain mental state". Thus, frighten is a psych verb in a sentence 'This science fiction film frightens Nina' since it means that Nina is in a certain mental state (i.e., fright) caused by the science fiction film; whereas visit is not a psych verb, on account of the fact that 'Charles visits Nina' involves no state of mind either of Charles or of Nina. ${ }^{1}$

1 According to Klein \& Kutscher (2005, p. 2), from the semantic point of view, psych-verbs can be sub-classified into verbs denoting emotions (love, frighten, etc.), perception verbs (see, taste, etc.), cognitive verbs (think, 
Psych-verbs may, in general, be divided into Subj(ect)Exp(eriencer) verbs and Obj(ect)Exp(eriencer) verbs, following the convenient terminology suggested in Pesetsky (1995), as illustrated in (1):

(1)

a. $\underset{\downarrow}{\downarrow}$ (Subject $\rightarrow$ Experiencer)

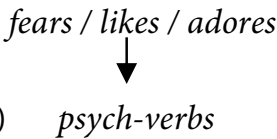

this science fiction film.

(Object $\rightarrow$ Cause / Target / Theme)

b. This science fiction film

(Subject $\rightarrow$ Cause / Target / Theme)
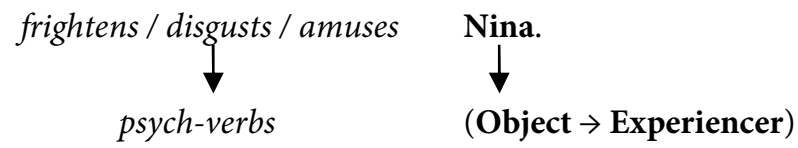

Interestingly, Fábregas \& Marín (2015, p. 169), in their recent paper, argue that "there is a core involved in all formal psych verbs (2a): a mental state which relates the Experiencer with the entity towards which this state is targeted." The core matches up the structure of SubjExp psychverbs, whereas ObjExp psych-verbs are built over this core by adding another layer codifying causation, but without any process (dynamic part) contained within the event structure, as illustrated in $(2 b){ }^{2}$

(2)

a.

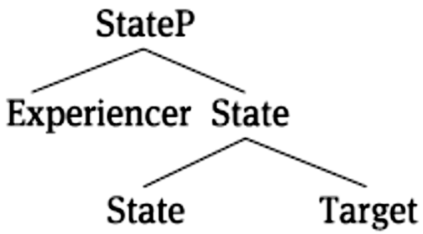

b.

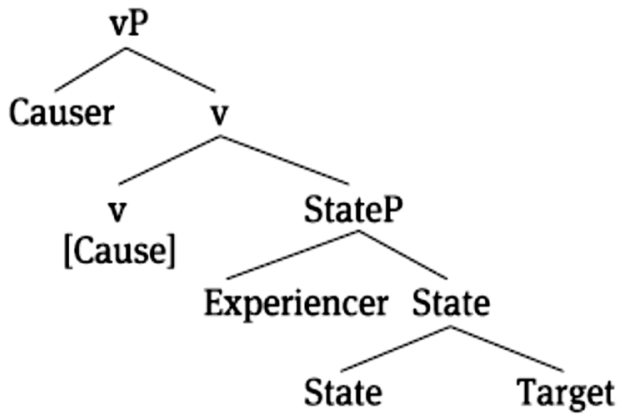

Consequently, Fábregas \& Marín (2015, p. 167) maintain that SubjExp psych-verbs denote individual level (IL) states, i.e., states without boundaries, whereas ObjExp psych-verbs should be classified as states of the stage level (SL) class since they denote states with an onset. ${ }^{3}$

Taking into account the relationship between the lexical properties of psych-verbs and their syntactic structure, i.e., remaining within the lexicon-syntax interface, Landau (2010, pp. 5-6), follows Belletti \& Rizzi's (1988, pp. 291-292) tripartite classification of psych-verbs, as displayed in (3), which I adopt for the sake of the paper.

assume, muse, etc.), and evaluating verbs (respect, appreciate, etc.). However, some of the verbs listed here do not satisfy Landau's definition of psych-verbs.

2 It was Pesetsky's (1995) original claim that ObjExp psych-verbs subsume SubjExp psych-verbs.

3 Class I (Subject Experiencer) verbs comprise individual-level and stage-level predicates (love vs. worry), and the latter are often related to inchoative (showing a process of beginning or becoming) or reflexive morphology, which is likely to have an agentive interpretation (cf. Pesetsky, 1995; Reinhart, 2002; Pylkkänen, 2000). 
(3) a. Class I: Nominative Experiencer, accusative Theme John loves Mary.

b. Class II: Nominative Theme, accusative Experiencer The show amused Bill.

c. Class III: Nominative Theme, dative Experiencer The idea appealed to Julie.

Class I Subject-Experiencer (SubjExp) psych-verbs include verbs like hate, love, or adore, which feature a nominative Experiencer, and an accusative Theme, as in (3a) and (4):

(4) Paul hates/adores/loves classical music. (Experiencer as the subject)

They are generally regarded as verbs similar to other transitive stative verbs (e.g. know). Landau (2010), similarly to Belletti \& Rizzi (1988), treats Class I SubjExp psych-verbs as regular transitive verbs. However, he adopts Arad's (1998) argument that even stative SubjExp verbs can denote locative relations. Thus, the Experiencer is either conceived of as the 'substance' contained in the mental state or the container in which the mental state resides, as illustrated in (5).

(5) a. Monica is in love (with Paul).

b. There is in him a great appreciation for artists.

(cf. Arad, 1998, p. 228, ex. 83)

Landau (2010, p. 17) argues that his contention that the Experiencer denotes a mental location holds true, even when the Experiencer occurs as a bare nominal, as in the case of SubjExp verbs in Hebrew, French and Navajo. He emphasises that in those languages and in many others there occur frequently periphrastic constructions, comprising the verbs be/have, a psych noun and an Experiencer location, as illustrated in (6a). Besides, in Irish and Scottish Gaelic, Experiencers are solely introduced by locative prepositions, as exemplified in (6b).

(6) a. Jean a peur de Marie.

Jean has fear of Marie

'Jean is afraid of Marie'

(Bouchard, 1995, p. 266, ex. 13a,g)

b. Tá eagla roimh $\mathrm{Y}$ ar $\mathrm{X}$.

is fear before $\mathrm{Y}$ on $\mathrm{X}$

' $\mathrm{X}$ is afraid of $\mathrm{Y}$ '

(McCloskey \& Sells, 1988, ex. 77a)

Exhibiting semantic parallelism with locations, even in languages like English, where they always take the nominative (non-oblique) form, SubjExps denote a path, either as a goal or a source, in contradistinction to non-Experiencer subjects, as in (7) (cf. Speas, 1990, ex. 3,7). 
(7) a. He got furious but it went away.

b. He tried to remember my name, but it wouldn't come to him. ${ }^{4}$

In addition, Landau (2010) emphasises the fact that SubjExps, which are stative transitives, behave in a unique way when they co-occur with a locative preposition5 (cf. Doron, 2003). Similarly, Fábregas \& Marín (2015, pp. 234, 265) make a proposal that SubjExp psych-verbs can also be captured in terms of a PP, as in (8a), following Landau's (2010) representation, or in their revised version, as in (8b).

(8) a.

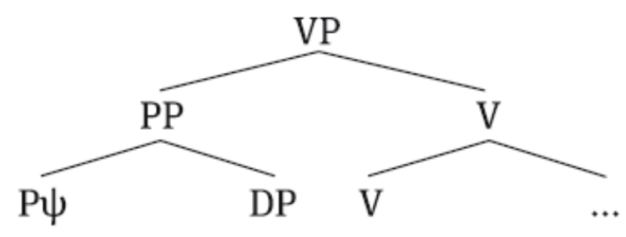

b.

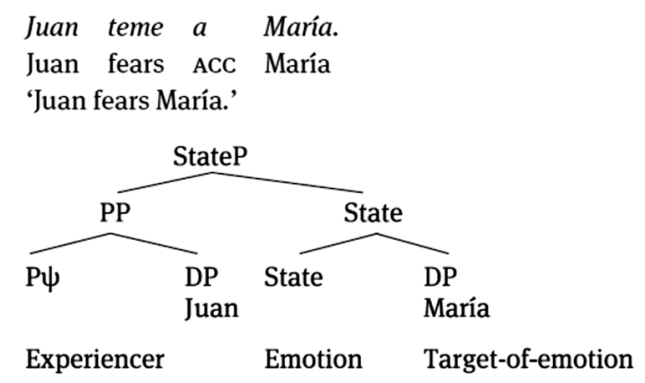

Nonetheless, both Landau's (2010) and Fábregas \& Marín's (2015) assumptions about the locative nature of SubjExps have not be proved by providing relevant evidence so far.

In a nutshell, it is the syntactic behaviour of Experiencer objects which deviates from that of canonical objects in various languages. ${ }^{6}$ For decades, these so-called psych effects have been studied in the theoretical as well as recent experimental research. The distinct properties of ObjExp psych-verbs will be of main interest in the subsequent section.

\subsection{Object-Experiencer verbs and their syntactic properties}

Limiting his analysis to the VP-structure, and following an extensive discussion in Pesetsky (1995) and Iwata (1995), Landau (2010, p. 8) claims that a psychological predicate is identified in the grammar by the presence of a specific structure, as presented in (9).

4 This evidence, as claimed by Speas, proves that dative SubjExps of South Asian languages (e.g., Malayalam) and the nominative SubjExps of English differ from each other strictly syntactically, while conceptually, in both languages Experiencers correspond to locations.

5 Cf. Landau's (2010, p. 13-15) analysis of Hebrew, in which there exists a paradigm of adjectival passives, beynoni $p a^{\prime} u l$, which expresses the verbal external argument in a $b y$-phrase. However, in the case of subject Experiencer verbs the preposition al-yedey 'by' is replaced by the locative preposition al 'on'. Consequently, the original object remains accusative, and the original subject - the Experiencer - becomes oblique, with the preposition al 'on'.

6 As stated by Landau (2010), the specific syntactic behaviour of ObjExp is best visible in peculiarities concerning binding, extraction/islandhood, reflexivization and argument linearization, etc. 
(9)

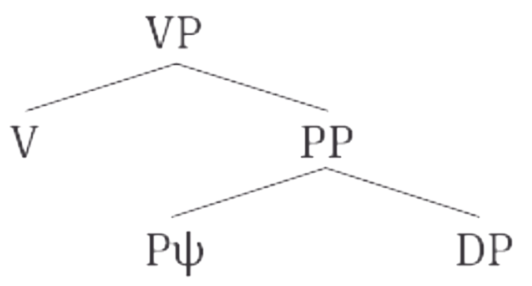

The structure in (9) is typical of ObjExp psych-verbs, and as a verbal structure it shows an Experiencer licensed by a prepositional structure. Besides, with this concrete structural representation for ObjExp psych-verbs in mind, Landau (2010, p. 8) offers more detailed structures in (10) and (11), with the structural analyses of both class II and class III verbs. He ascertains that psych-verbs of class II and III are special due to the oblique nature of their Experiencers.

With class III verbs, classified as unaccusative, for most languages, the Experiencer is either encoded by means of an oblique case (often dative) or by means of a PP, following Belletti \& Rizzi (1988), Pesetsky (1995), and Arad (1998), among others. This assumption is also made by Landau (2010, pp. 19-20), who points out that object Experiencers universally bear inherent case, and that inherent case is universally assigned by a P. In class III verbs, the theme argument of these verbs is not a Causer but rather a Target/Subject Matter, T/SM (Pesetsky, 1995). Besides, in languages where the dative marker is not an independent preposition, class III Experiencers are governed either by a lexical preposition (English) or a null preposition $\varnothing \psi$ (in languages with morphological case), which assigns the dative case. The VP structure of this type of psychverbs is then as in (10).

(10)

Class III verbs - unaccusatives

$$
\begin{array}{cl}
{\left[\mathrm { vp } [ \mathrm { pp } \text { P DP } ] \left[\mathrm{v}^{,} \mathrm{V}\right.\right.} & \mathrm{DP}]] \\
\text { Experiencer } & \text { Theme }
\end{array}
$$

(Landau, 2010, p. 8, ex. (12b))

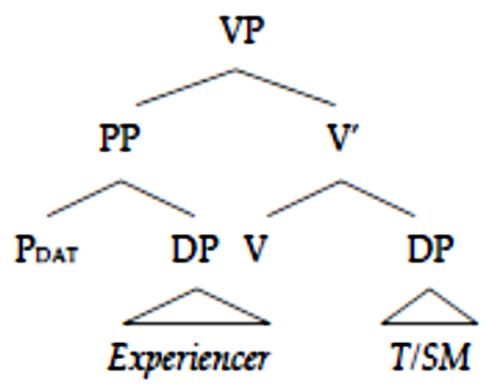

In (10), the Experiencer may move overtly to the subject position (depending on the language), resulting in the so-called 'quirky' subjects, or covertly, forming the "second" subject (Landau, 2010, p. 88). The latter case is valid for languages like English, which prohibit case-marked Determiner Phrases (DPs) in the specifier of Tense (Spec,TP)). In English, the theme argument raises to [Spec,TP] overtly, and the Experiencer raises to a second [Spec,TP] at LF. This effect not only creates a multiple-specifier structure, but it also can be called LF-quirkiness (Landau, 
2010, p. 87). Besides, class III ObjecExp verbs are stative unaccusatives, which means that they can never be used agentively.

Undeniably, the oblique nature of Experiencers is much less obvious with class II verbs, which in many languages apparently occur with nominal (accusative) object Experiencers. Landau (2010) classifies class II verbs into three groups: (i) stative verbs like interest, concern, depress, which are unaccusatives and have the same structure as class III verbs (except that the Experiencer with these verbs is governed by a null P). Moreover, (ii) the second and the major group contains eventive non-agentive verbs like frighten, anger, surprise, which in the transitive use have a Causer as an external argument, projecting a light $v$ (cf. Arad, 1988; Pesetsky, 1995; and Iwata, 1995, among others), and the Experiencer as an oblique object, as represented in (11).

Class II verbs - transitives

$\left[\mathrm{vp}\right.$ DP [ ${ }^{\prime} \mathrm{V}[\mathrm{vp} \mathrm{V}[\mathrm{pp}$ P DP $\left.\left.]]\right]\right]$
Causer $\quad$ Experiencer

(Landau, 2010, p. 8, ex. (12b))

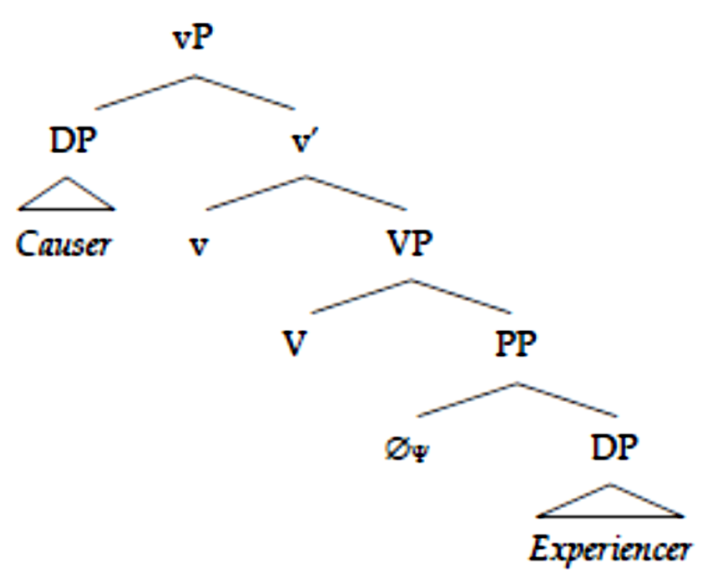

The third (iii) group of class II verbs comprises eventive agentive verbs, considered to be regular transitive verbs that take a direct object. This class differs from non-agentive predicates since it does not show the special syntax of psych verbs. Accordingly, even though some class II verbs are only either stative (concern) or eventive (startle), the borderline is not clear-cut as some verbs in class II are ambiguous, or allowing for both stative and eventive readings (frighten). Landau (2010, pp. 55-56) underlines that, in fact, most class II verbs are ambiguous, to varying degrees, between stative and eventive readings. The unaccusative status is exhibited empirically only by those verbs (like concern, interest) which are unambiguously stative. Thus, he assumes that only stative class II verbs lack, in their thematic grid, a causer argument, which is the source of eventive interpretation. ${ }^{7}$

7 For Italian, Belletti \& Rizzi (1988) identify Class I of psychological verbs as the one with the uncontroversial transitive structure, since the Experiencer has the external $\theta$-role, and no inherent Case is assigned. Class II and class III of psych-verbs, with no external $\theta$-role, and the Experiencer related to an inherent Case (accusative and dative), are associated with, according to Belletti \& Rizzi (1988), an unaccusative structure. 
Generally speaking, these special psych properties, restricted to ObjExp verbs, as argued by Landau (2010, pp. 127-128), are related to the presence of a (possibly null) locative preposition with a [loc] feature, governing the ObjExp. Accordingly, the absence of these properties must be a sign of the absence of the preposition; thus, agentive contexts (with no psych properties) exclude the psych-preposition. Besides, due to locative inversion an Experiencer object in class II verbs is raised to the subject position, while all Experiencers become LF-subjects, taking [Spec, TP], as shown in (12a-b) for eventive and stative psych verbs.

a. Eventive psych-verbs: LF

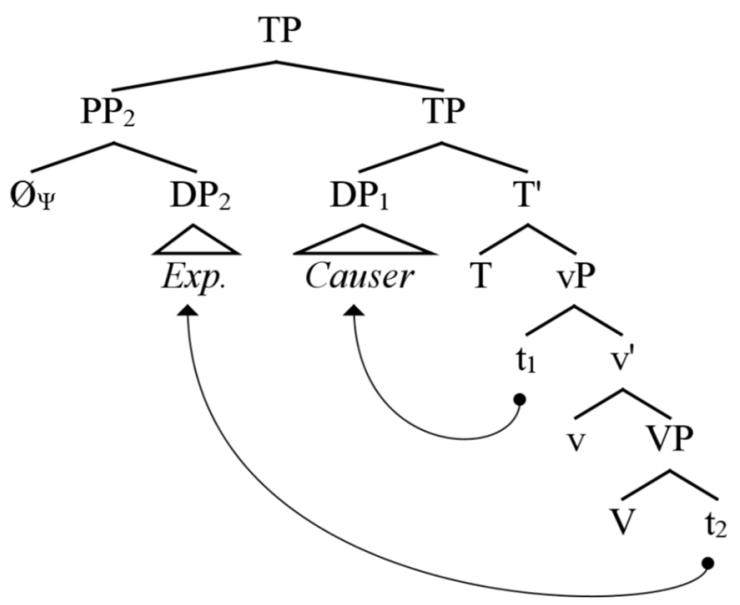

b. Stative psych-verbs: LF

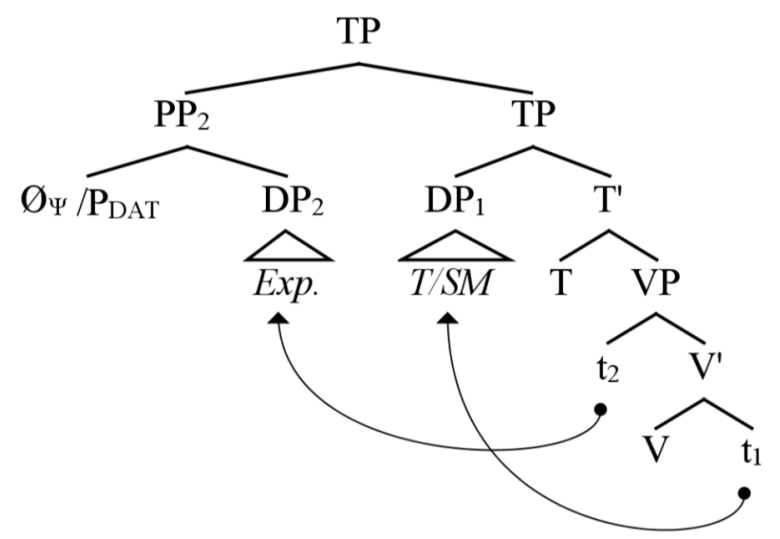

What is more, refuting Belletti \& Rizzi's (1988) assumption about the unaccusative status of psych verbs of eventive class II, ${ }^{8}$ Landau (2010) claims (following Pesetsky, 1995) that most

8 Landau (2010, pp. 19-20) deals with Belletti \& Rizzi’s (1988) claim concerning the unaccusativity of II and III class psych-verbs. He says that it is unproblematic for class III verbs, which assign dative case to the experiencer and select the auxiliary essere. Nonetheless, class II verbs with these two properties are never found: they select the auxiliary avere, and assign the accusative case, violating Burzio's (1986) generalization. The second problem relates to the fact that class II verbs assign inherent accusative, which Landau (2010) takes for granted, similarly to Belletti \& Rizzi (1988), while Burzio's generalization only regulates the assignment of structural accusative. Thus inherent accusative can be assigned even in the absence of an external argument. 
class II verbs are not unaccusatives. Besides, he proposes that, commonly, non-nominative Experiencers bear inherent case, which is assigned by a P (cf. Emonds, 1985). This implies that nominals marked for inherent case are always dominated by a PP node. This PP may be headed by a lexical P (as in English obliques) or a null P (as in Latin obliques), but both cases are structurally distinct from bare DPs (Landau, 2010, pp. 21-22).

Additionally, providing a wide range of syntactic properties of ObjExp verbs in different languages, from a variety of perspectives, Landau (2010) makes an attempt to prove that Experiencers behave like datives/PPs, i.e., locatives. Such psych properties are divided, according to Landau (2010, pp. 75), into core and peripheral ones, with a distinction which languages they are typical of, as in (13):

(13) A classification of Psych Properties

(I) Core Properties

(a) All Class II Verbs (Non-agentive)

1. Overt obliqueness of Experiencer (Navajo, Irish, Scottish Gaelic).

2. Accusative / Dative alternations (Italian, Spanish).

3. Islandhood of Experiencer (Italian, English).

4. PP-behavior in $w h$-islands (English, Hebrew).

5. No synthetic compounds (English).

6. No Heavy NP Shift (English).

7. No Genitive of Negation (Russian).

8. Obligatory clitic-doubling (Greek).

9. Obligatory resumption in relative clauses (Greek, Hebrew).

10. No si/se-reflexivization (Italian, French).

11. No periphrastic causatives (Italian, French).

12. No verbal passive in type B languages (Italian, French, Hebrew).

(b) Class III and Stative Class II (Unaccusatives)

1. No verbal passive (English, Dutch, Finnish).

2. No periphrastic causatives (French, Italian dialects).

3. No forward binding.

(II) Peripheral Properties

1. The T/SM restriction.

2. No causative nominalizations.

3. Backward binding.

(Landau, 2010, p. 75)

All the core psych properties can be encountered only in non-agentive contexts, while if an agentive context appears, a class II verb behaves like any ordinary transitive verb (cf. Belletti \& Rizzi, 1988; Grimshaw, 1990; Bouchard, 1995; Arad 1998, 2000; Landau, 2010). While Belletti \& Rizzi (1988) and Arad (1998) associate all the special psych properties with the unaccusative nature of class II verbs, actually the single issue of unaccusativity cannot distinguish agentive from non-agentive class II verbs in the general case (cf. Pesetsky, 1995). Instead, Landau (2010, p. 129) assumes that 'the agentivity puzzle' should be resolved with the meaning shift from a non-agentive to an agentive reading of a class II verb, which is complemented with an aspectual shift, as stated in (14). 
(14) a. Agentive class II verbs are change-of-state verbs (i.e., accomplishments).

b. Non-agentive class II verbs are states or achievements.

Accordingly, ObjExp verbs on the agentive interpretation are change-of-state verbs, i.e., accomplishments. In the agentive context, the Experiencer who undergoes the change of state, becomes an affected argument, i.e., a direct object (Dowty, 1991), a bare DP Experiencer. As a result, Experiencer objects of agentive class II verbs cannot raise to the subject position since they are bare nominal receiving structural accusative case. In turn, non-agentive class II verbs are states or achievements (Landau, 2010, pp. 129-131). ${ }^{9}$ The special behaviour of psych verbs, i.e., their genuine psych-effect, is restricted to non-agentive contexts (subject as a theme), whereas when the predicates are used agentively, the subject is a volitional agent while the Experiencer plays the role of a patient.

Furthermore, Landau (2010, pp. 18-19) claims that an oblique construction forces a nonagentive reading, but a transitive construction does not force an agentive reading. Thus, the oblique Experiencer correlates with a non-agentive subject. Indeed, non-agentive ObjExp constructions are universally oblique. For most languages, the preposition governing the Experiencer is null $(\varnothing \psi)$, i.e., it involves a PP headed by $\varnothing \psi$ (as in English). The 'psych' prepositions have different versions across languages; however, Irish psych predicates are special since that preposition is overt (usually, ar 'on'). In short, all class III verbs are stative (unaccusative), and never used agentively, while most class II verbs are ambiguous between the three readings, i.e., (i) stative (unaccusatives), (ii) eventive agentive (regular transitives), (iii) eventive non-agentive (stative / transitive).

To conclude, Landau (2010, p. 131) argues that it is the Experiencer that undergoes the change of state in the agentive context, contrary to the Experiencer in non-agentive (class II) contexts, which does not undergo a change of state in the aspectually relevant sense. Instead, it is either a locus where a mental state resides (statives) or appears (achievements). In these socalled 'locative' contexts, $\varnothing \psi$ is a crucial interpretive ingredient.

\subsection{Syntactic properties of English psych-verbs}

Based on the core and peripheral properties, reproduced in (13), which Landau (2010, p. 75) lists as typical of psych-verbs, syntactic diagnostics can be set to distinguish psych-verbs from other verbs, and non-agentive from unaccusative psych-verbs. Five of the core properties are applicable to characterise English psych-verbs, as illustrated in (15).

a. All Class II Verbs (Non-agentive)

i. Islandhood of Experiencer

ii. PP-behaviour in wh-islands

iii. No synthetic compounds

iv. No Heavy NP Shift

This approach is compatible with Marín \& McNally's (2011) account and an earlier analysis of psych verbs offered by van Voorst (1992). For a further discussion upon the aspectual properties of psych verbs cf. Grimshaw (1990), Pesetsky (1995) and Pylkkänen (2000), among others. 


\section{b. Class III and Stative Class II (Unaccusatives) \\ i. No verbal passive (English, Dutch, Finnish).}

Even though prepositional objects in English are not strong islands, some cases may be acceptable, as in (16).

(16) a. * Which film was Dirk amusing to the director of?

b. Which film did Sam entrust Marilyn to the director of?

(Roberts, 1991, ex. 43a,c)

Landau (2010, p. 29) points out, citing Roberts' (1991) examples in (16), that the Experiencer shows islandhood as an object of a non-agentive psych predicate, as in (16b), but not as an object of an agentive predicate, as in (16a) (cf. Johnson, 1992 and Stowell, 1986).

More to the point, the PP-like behaviour of class II non-agentive psych-verbs in $w h$-islands is illustrated in (17). The data in (17) allow us to conclude that English treats accusative Experiencers as PPs in certain contexts. Landau (2010, pp. 29-30) makes a claim that Experiencer objects behave like adjuncts since they are more resistant to extraction from whislands than other direct objects. Nevertheless, (17b) gives the impression that its illformedness, even though greater than that of (17a), is not as strong as that of standard adjunct extraction out of a wh-island (17c), but it still seems to have just the status of PP-extraction (17d).

(17) a. ?? Who did you wonder whether Sam knew?

b. ?* Who did you wonder whether the book bothered?

c. ${ }^{*}$ Why $y_{1}$ did you wonder whether the book appealed to Sam $t_{1}$ ?

d. ?* To whom did you wonder whether the book appealed $t_{1}$ ?

(Johnson, 1992, ex. 25a, 26a)

(Landau, 2010, ex. 60)

Landau (2010, pp. 29-30) argues that the kind of violation exhibited in PP-extraction in (17d) is as unacceptable as extraction of genuine Experiencer direct objects, which he proposes as proof for his analysis of Experiencers as arguments of null prepositions. Landau offers a syntactic analysis of English ObjExp verbs in which they do not take complement NPs (or DPs) as do canonical transitive verbs, but instead select for PP complements headed by a null preposition $(\varnothing \psi)$. As a result, since objects of ObjExp verbs are arguments of null prepositions, extraction from within these null-headed PPs should reveal the same degree of unacceptability as extraction from overt-headed PP complements found with other verbs. ${ }^{10}$

${ }_{10}$ Moreover, Landau (2010, pp. 30-31) analyses some other peculiarities of ObjExp verbs, which are skipped here due to the lack of space in this paper. This is their inability to form synthetic compounds, involving a deverbal head and its object (a god-fearing man, a fun-loving teenager, ${ }^{*}$ a man-frightening god, ${ }^{*}$ a parent-appalling exploit). Another characteristic of ObjExp verbs is their resistance to Heavy NP Shift (HNPS), analogous to the inner object in the double object construction, e.g. * These things bothered yesterday the man who visited Sally.I * We told these things (yesterday) the man who visited Sally. While overtly prepositional experiencers, as in These things appealed yesterday to the man who visited Sally, are perfectly moveable.

Nonetheless, Grafmiller (2013, pp. 69-71) finds in the web corpora some acceptable examples of shifted Experiencer objects no worse than shifted examples of other kinds of affected objects. However, he leaves the 
Furthermore, Landau (2010) faces the controversial question of whether class II verbs have a verbal passive. This is where the subdivision of class II into three groups becomes vital, (i) stative class II verbs (and all class III verbs) generally fail to passivize since they are unaccusative; (ii) agentive eventive class II verbs are normal transitive verbs and therefore universally allow passivization; (iii) non-agentive eventive class II verbs which are not unaccusative, allow pseudopassives, i.e., prepositional passive in which the object of a preposition takes the position of the subject of a clause. However, the verbs with the oblique nature of Experiencers are expected not to passivize unless the language can resort to special strategies, presented in (18) (cf. Landau, 2010, p. 48).

(18) a. P-stranding: The preposition that governs the object is stranded and reanalysed with the verb - only available in languages where $[\mathrm{V}+\mathrm{P}]$ reanalysis can feed $\mathrm{A}$-movement.

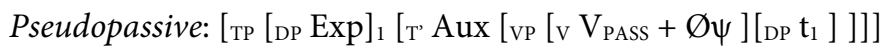

b. Pied-Piping: The preposition that governs the object is carried along to the subject position - only available in languages licensing quirky subjects.

Quirky passive: [TP [pp $\left.\varnothing \psi\left[{ }_{\mathrm{DP}} \operatorname{Exp}\right]\right]_{1}\left[\mathrm{~T}^{\mathrm{T}}\right.$ Aux [vp $\left.\left.\left.\mathrm{V}_{\mathrm{PASS}}\left[\mathrm{pP}_{\mathrm{p}} \mathrm{t}_{1}\right]\right]\right]\right]$

English can be classified as a type A language, i.e., allowing pseudopassives, e.g., This armchair was sat in./Monica can be put my faith in.

Only non-stative psych verbs passivize, while stative class II verbs do not passivize due to the fact that they lack an external argument. ${ }^{11}$ Consequently, the tests to distinguish stative from non-stative class II verbs are important. Landau (2010, p. 49) mentions that in English the progressive form is a standard test for non-statives. In the sentences Landau (2010, p. 49) provides: (i) The situation is depressing Mary; (ii) * Mary is being depressed by the situation, the verb depress is seen as not stative in the active (i) version, since it can appear in the progressive. Nevertheless, its passive form, as in (ii) is stative, and cannot occur in the progressive; even though it is well-known that verbal passivization does not change verbs from stative to nonstative or the other way round. For that reason, as justified by Landau (2010, p. 50), the passive in the sentence (ii) must be adjectival, explaining its stativity (cf. Grimshaw, 1990, p. 114).

On the other hand, class II verbs vary in their stative behaviour, as illustrated in (19).

(19) a. Sue was continually being scared by odd noises.

b. Harry is clearly fearing an outbreak of the flu.

c. * An outbreak of the flu is clearly being feared by Harry.

d. An outbreak of the flu is feared by Harry.

(Pesetsky, 1995, ex. 73a, 75e, 76e, 77e)

Contrasting depress (which is strongly stative), the verbs scare, terrify, shock and surprise reveal an eventive reading both in active and passive, as in (19a). Additionally, as noticed by Landau

case open, concluding that whatever differences in the judgments of these sentences there may be, they are far too subtle to draw strong conclusions about (potentially covert) aspects of their syntactic structure.

11 Thus, Landau (2010: 49) reduces the generalization in (i) to the one in (ii).

(i) Universally, stative class II verbs do not passivize.

(ii) Universally, stative class II verbs are unaccusative. 
(2010, pp. 50-51), English is expected to have eventive verbal psych passives since their verbal status is proven by the fact that these passives in the progressive are incompatible with special idiosyncratic prepositions, as in (20). ${ }^{12}$

(20) a. Bill was enraged by/at totally innocent remarks.

b. Bill was often being enraged by ${ }^{\star}$ at totally innocent remarks.

(Landau, 2010, pp. 57-58)

Landau (2010, p. 57) claims that such idiosyncratic prepositions are a proof of adjectival passives, which are lexically derived; thus (20a) sounds grammatical. On the other hand, these prepositions are disallowed in contexts that force the choice of a verbal passive, like the progressive aspect, given in (20b).

Besides, Landau (2010, pp. 50-51) notes that in order to discern between stative and eventive readings, it is better to use a pseudocleft test, which is less problematic than the progressive test. Pseudo-cleft structures (also called wh-clefts), formed with the pronoun what (= the thing(s) that/which), emphasise an action itself that follows the whatclause $+b e$. As illustrated in (21a), stative verbs fail the test, whereas eventive class II verbs pass it, as shown in (21b).

(21) a. * What that solution did was escapelelude/concern Mary.

b. What that noise did was scare/surprise/startle Mary.

Interestingly, Landau (2010, p. 51) points out that Pittsburghese dialect of English provides further evidence as for eventiveness, rather than agentivity of verbal psych passives. In her analysis of this dialect, Tenny (1998) explains, on the basis of some contraction that selects for verbal passive participles, that the construction is well-matched to eventive adverbials, progressive aspect and idiom chunk passives, and mismatched with the adjectival un-passive, as in (22a-d) respectively.

(22) a. The dog needs scratched hard.

b. The car has been needing washed for a long time now.

c. Tabs need kept on the suspect.

d. ${ }^{*}$ The house needs unpainted.

${ }^{12}$ Analysing further examples, as in (i), Pesetsky adds that some class II verbs do not form passives at all, similarly to class III verbs that never pseudopassivize (31c-e) (cf. Perlmutter \& Postal, 1984). These facts make Pesetsky suggest that all these verbs are unaccusative as they do not form passives.

(i) a. * We were escaped by Smith's name.

b. ${ }^{*}$ Panini was eluded by the correct generalization.

c. ${ }^{*}$ Mary wasn't appealed to by the play.

d. ${ }^{*}$ John was mattered to by this.

e. * Mary was occurred to by the same idea.

(Pesetsky, 1995, ex. 153b, 154b, 155b, 156b, 157b)

Further evidence for the unaccusativity of escape and elude comes from the fact that they do not form middles or -er nominals (similarly to concern and interest), as in (ii) (cf. Pesetsky, 1995).

(ii) a. ${ }^{*}$ Great ideas elude/escape/concern/interest easily.

b. ${ }^{*}$ an eluder, ${ }^{\star}$ an escaper, ${ }^{\star}$ a concerner, ${ }^{*}$ an interested. 
Besides, class II passives are commonly recognised in this construction, e.g., Nobody needs angered/irritated/discouraged/dismayed by the truth. If this is true, then Pesetsky's view wins over Grimshaw's, and English eventuality of verbal passive over non-stativity in class II verbs is justified. Indeed, the more eventive the verb, the more felicitous verbal passives are, even though Tenny (1998, p. 595) truly notes that "a complex of factors influences the degree of eventiveness, including not only agentivity but also volitionality, punctuality, and the affectedness of change of state in the experiencer. ... Individual speakers vary in how strict they are with this scale in making verbal passives." Consequently, Landau (2010, p. 51), relying on Tenny's (1998) analyses, makes a conclusion that English provides evidence from independent sources for the possibility of verbal passive on non-stativity in class II verbs.

In addition, Verhoeven (2010, pp. 18-19, 42-44) carried out some diagnostic tests for agentivity and stativity, in order to identify semantic properties of particular verbs of different psych-verb classes in five different languages. Especially in those languages which display a grammaticalized expression of the progressive aspect, the verbs were tested within the corresponding constructions. Thus, three standard diagnostic tests that were implemented in this study comprise, first, the VOLITIONALITY TEST, which examines the compatibility of the verb with an adverb denoting the volitional involvement of the actor, e.g., the adverb intentionally. Then the IMPERATIVE TEST was to examine whether an order can be expressed by using the imperative form or construction of the verb and provide further evidence for the possibility of an agent to have volitional control over the event. Finally, the STATIVITY TEST was meant to examine whether the verb can be used in a form or context that implies a dynamic internal temporal structure of the event.

In a nutshell, Landau's generalization regarding type A languages that the passive in class II is only found with eventive verbs, while stative verbs are unaccusative, has been shown to be true. Also, Landau's (2010, p. 51) thesis 'the more eventive the verb, the more felicitous verbal passives are' is adequate. ${ }^{13}$ Indeed, the picture concerning the passivization of psych-verbs is thus fairly intricate, with unaccusativity and obliqueness of the Experiencer being the two major factors governing the cross-linguistic and mono-linguistic variations.

13 Grafmiller (2013, pp. 69-86) confirms that the semantic distinction between the stative (adjectival) and eventive (verbal) uses of the past participle is subtle, and over the years various grammatical diagnostics have been proposed for distinguishing between them syntactically. He cites four criteria for identifying adjectival passives: (i) Use as prenominal modifiers; (ii) Use as the complement of verbs such as seem, look, sound, and act; (iii) Prefixation with un-; (iv) Modification with the degree adverb very. These environments are alike in that they all share the property of selecting adjectives and not verbs. Taken together, the facts all lead to the conclusion that ObjExp verbs, like many other causative verbs, readily form adjectival passives. Besides, Grafmiller (2013, pp. 87-96) claims that at least some ObjExp verbs can form verbal passives. The use in the iterative progressive, the punctual past, and the needs $V$-ed construction all require supposedly eventive interpretations of the predicate, and therefore are diagnostics of verbal passives. Finally, Grafmiller (2013, p. 111 (ex. 3.65a)) proves that any Obj-Exp verb can be used in the progressive passive with an iterative interpretation - even those that are most frequently claimed to denote states, e.g. bore, concern, depress and worry (If you turn on the TV and are continually being bored by the programming, it's likely you have the wrong type of cable package). Thus, his analysis of corpus data shows that eventive and stative uses are available to all Obj-Exp verbs in both the active and passive, which runs counter to many author's claims (Arad, 1998; Bouchard, 1995; Landau, 2010). 


\section{Psychological predicates and their phraseological counterparts}

\subsection{Theoretical background}

In Landau's (2010, p. 6) account, Experiencers are regarded as mental locations - locatives, i.e., containers or destinations of mental states or effects. Consequently, Landau makes a claim that (i) all Object Experiencers are oblique (or dative); (ii) Experiencers undergo "locative inversion" (ibid., p. 6). This standpoint is compatible with Jackendoffs (1990, p. 300 n4) decomposition approach in which the relation between an Experiencer, and a non-Experiencer argument (called stimulus, trigger of emotion, causer or target/subject matter, or theme) (Landau, 2010, p. $10)$, can be presented in terms of a conceptual representation in (23b), roughly read as in (23c).

(23) a. X frightens $\mathrm{Y}$.

b. $\left[\mathrm{CS}^{+}\left([\mathrm{X}]^{\alpha}\right.\right.$, [INCH $\left.\left.\left.[\mathrm{BE}([\mathrm{FEAR}([\alpha])],[\mathrm{AT}[\mathrm{Y}]])]\right]\right)\right]$

c. $\mathrm{X}$ causes fear of $\mathrm{X}$ to come to be in $\mathrm{Y}$.

On the basis of (23), Jackendoff (1990) notices that the mental state itself is somehow extracted from the verb, becoming a co-argument of the Experiencer. The Experiencer itself appears to be the object of a preposition, which locates the mental state within it (cf. Baker (1997) for a similar suggestion, Iwata's (1995) 'reversed' option for the Experiencer to be placed within the mental state). Even though in Jackendoff's (1990) analysis the target of fear equals its cause, Pesetsky (1995) does not find this equation necessary.

Besides, Bouchard (1995, p. 272) treats the mental state as an independent semantic argument, called psy-chose, which he also names a syntactic argument "...in mental space, the psy-chose is somehow put in contact with the argument it affects." This argument, as a unit able to absorb the emotion or feeling that the psy-chose denotes, stands on its own, as in the periphrastic psych construction, as in (24a), or is represented in the verb, as in standard ObjExp verbs, as in (24b).

(24) a. Cela a éveillé en Pierre une rage terrible.

'That awoke in Pierre a terrible rage'

b. Cela a enragé Pierre.

'That enraged Pierre'

(Bouchard, 1995, p. 275, ex. 35a,c)

Landau (2010, p. 10) further assumes that despite the fact that psych-verbs are decomposed conceptually into an 'action' light verb plus a mental state (psy-chose), this does not imply that this decomposition happens on the syntactic level as well. ${ }^{14}$ Instead, the locative preposition is

14 Landau (2010, p. 137 fn. 2) assures that, actually, some evidence has been provided to justify the claim that periphrastic and synthetic psych constructions have different forms in some semantic aspects that cannot be ascribed as the single factor of incorporation. While in non-agentive contexts, periphrastic forms are telic, synthetic forms are not.

i. The movie horrified / enraged Mary for/*in 15 minutes.

ii. The movie filled Mary with horror / awoke rage in Mary in/^for 15 minutes. 
syntactically active no matter if the Experiencer is a bare nominal or not, while syntactic activity happens in the mental state only when it is visible, i.e., in periphrastic constructions. ${ }^{15}$

\subsection{The aim of the research}

On the ground of these fundamental assumptions of Landau's (2010) localist and decomposition theory of psych-verbs, it is time to open a discussion upon phraseological verbal units which display a psychological condition, providing the overall meaning of the idiom, not only the meaning of its individual items is taken into consideration. The hypothesis I would offer implies that some phraseological units that comprise a verb and PP may be treated as a periphrastic construction related to a certain standard psych-verb, in which the Experiencer is a mental location. ${ }^{16}$

The universal present-day English tends to be more idiomatic, thus, indeed, it seems to be worth paying attention to the role phraseological units play in a language. Undoubtedly, it is difficult to speak or write English without using idioms, especially while describing one's emotional or mental condition. Thus, the purpose of section 3.4 is to collect as many phraseological items as possible, that begin with a verb, and that bear a meaning comparable to psychological predicates. The study aims at providing an answer to the following questions:

Q1. Are there any V + PP idiomatic expressions that can be used instead of common psychological predicates to express one's mental or/and emotional condition?

Q2. Taking Landau's (2010) localist approach as the basic assumption, can we find in those psychological verbal idiomatic units a participant, an Experiencer, who is an emotional or mental location?

Q3. Provided the special syntactic behaviour, i.e., psych effects, are typical of Experiencer objects, ${ }^{17}$ and are universally only associated with the non-agentive reading in those predicates (Landau, 2010), what is the syntactic status of those ObjExp idiomatic units?

Having set the aims to achieve, let us turn now to establish some working definitions and analyse the relevant data.

Simple N-to-V incorporation does not imply such aspectual shifts.

15 Bouchard's syntactic decomposition has been adopted by Arad $(1998,2000)$ as well, but it should not be driven only by semantic aspects.

${ }^{16}$ I thank the anonymous reviewer of this article for his/her suggestion that Lakoff (1987) and Lakoff \& Johnson (1980 a, b), among others, additionally motivate the use of idioms as linguistic evidence, when they claim 'transparent' idioms to be motivated by conceptual structures (cf. Keysar \& Bly (1999) for a different view).

${ }^{17}$ For the purpose of the paper, the analysis of Subject Experiencer predicates is abandoned, since their psycheffects are not unanimously proven, and the Experiencer in the subject position is not justified as a mental location. 


\subsection{Working definitions}

For the sake of this paper, the working definition of idiomatic expressions is adopted after O'Dell \& McCarthy (2010, p. 6), who identify idioms as "fixed combinations of words whose meaning is often difficult to guess the meaning of each individual word." Idioms with their regular or irregular structures, logical and grammatically correct or incorrect forms (Seidl \& McMordie, 1978, p. 5) give the unique flavour to the language used in everyday life. Truly, in some cases idiom constituents do not contribute to the overall meaning of the idiomatic phrase, then it should be recognised as a metaphor and a cohesive entity treated as a whole.

Besides, the next crucial definition used in the study, and already introduced in section 2 of the paper, concerns psych-verbs. Thus, at this point, the term is only briefly characterised. Guidi (2011, p. 30), on the basis of well-known approaches represented by Belletti \& Rizzi (1988), Pesetsky (1995), and Landau (2010), among others, defines psych-verbs as verbs that express (a change in) mental or/and emotional states and a relation between an Experiencer and the Cause/Theme of such a psychological state. Fábregas \& Marín (2015, p. 172) add that verbs which involve mental states but their arguments do not behave in any exceptional way are not true psychological verbs from the syntactic perspective, due to the lack of psych effects.

\subsection{Data collection and methodology applied}

The research reported here is based on English data collected from English dictionaries of idiomatic expressions, such as (i) Seidl \& McMordie's (1978) English Idioms and How to Use Them (Fourth Ed.) by Oxford University Press; (ii) Wielki multimedialny słownik angielskopolski i polsko-angielski. [Great Multimedia English-Polish and Polish-English Dictionary] (2005) by PWN-Oxford; and (iii) O’Dell \& McCarthy's (2010) English Idioms in Use Advanced by Cambridge University Press. The first dictionary has been chosen as a reliable source, since this reference book provides information about over 3000 idioms and the context of their usage. The second reference book has been chosen on account of the fact that in its CD-ROM version it contains more than 500000 English and more than 500000 Polish units, coming from all varieties of language and it illustrates their typical uses in grammatical constructions. Finally, the third source, i.e. O'Dell \& McCarthy's (2010) book, has been chosen as the final filter to check the idioms under scrutiny in the native-like contexts. It presents and practises over 1000 of the most useful and frequent idioms in typical situations, used at an advanced level.

All of these dictionaries have been supported with the Corpus of Contemporary American English (COCA) to prove the reliability of the study. Thus, the items found in the dictionary were then checked in terms of the possibility of their occurrence, frequency and context. The corpus displays also the information regarding the source and period of the emergence of an entity. The database of the COCA includes 450 million words from the period 1990-2012, and has a direct link to the New Wikipedia Corpus, which gives a quick and easy access to the virtual corpora from the 4.4 million articles in Wikipedia (1.9 billion words), and to Google Books Corpus, which covers 189 billion words from British and American English altogether.

The study focuses on instances where a psych meaning occurs within idiomatic expressions that begin with a verb. Such phraseological units, similarly to psych predicates, comprise a 
participant, in an object position, who experiences some emotional or mental state, i.e., an Experiencer, and a Stimulus/Causer/Cause that has just contributed to such a state, as illustrated in (25):

(25) $\mathrm{X}^{18} \quad$ [frightens / disgusts / encourages, etc.] $\mathrm{Y} \quad$ (Object Experiencer $\left.(\mathrm{Y})\right)$

Accordingly, in line with the localist approach postulated by Landau (2010), the Experiencer is expected to become a location of the psychological condition. The collection of idioms comprises any idiomatic expressions that display a structure $\mathrm{V}+\mathrm{PP}$, including phrasal verbs that are listed as idioms in the source dictionaries of idiomatic expressions. Although the goal was to include as many tokens as possible, proverbs and some verbal idiomatic expressions have been omitted due to their vague psychological meaning or/and obvious physical action involved, which makes the experienced mental or emotional state only of a supportive meaning, instead of primary one (e.g., abandon, argue collocations). From the semantic point of view, the data includes the idiomatic instances which denote both positive psychological condition (X pleases $\mathrm{Y}$ ), 'mild' (X upsets $\mathrm{Y}$ ) ones, until some strong negative emotions can be reached (X frightens $Y$ ). The meanings of those units are exemplified in sentences, taken from the Google Corpus. The data with lexical/explicit PPs are provided in (26), while the phrases, in which the preposition is null/implicit are gathered in (27).

\section{(26) Psychological ObjExp idiomatic phrases with lexical/explicit PPs}

1. $\mathrm{X}$ sets $\mathrm{X}$ 's cap at $\mathrm{Y}$ (to attract $\mathrm{Y}$ ) She was never known to set her cap at any man, and her conversation is always so negligently sensible.

2. $\mathrm{X}$ is music to Y's ears (to make $\mathrm{Y}$ excited)

The news of their director's resignation was music to his ears.

3. $\mathrm{X}$ turns on $\mathrm{Y}$ (to get $\mathrm{Y}$ engaged, attract $\mathrm{Y}$ )

That sly smile of hers could turn on you.

4. $\mathrm{X}$ is a slap in the face for $\mathrm{Y}$ (to be upsetting for $\mathrm{Y}$ )

Losing the election was a slap in the face for the club president.

5. X treads on Y's toes/corns (to upset $\mathrm{Y}$ )

He is very proud of the modern paintings in his house, so don't tread on his toes by making funny remarks about them.

6. $\mathrm{X}$ bears down on $\mathrm{Y}$ (to scare $\mathrm{Y}$ )

You should bear down on your students the week before examinations.

7. $\mathrm{X}$ gets at $\mathrm{Y}$ (to criticise or make fun of $\mathrm{Y}$, or to intimidate $\mathrm{Y}$ )

He's always getting at me!

8. $\mathrm{X}$ goes on at $\mathrm{Y}$ (to scold, bother $\mathrm{Y}$ )

It's too early to go on at you about learning lessons from this experience.

9. $\mathrm{X}$ is on at $\mathrm{Y}$ (to make $\mathrm{Y}$ frightened/ under pressure)

He's always on at me about it.

10. $\mathrm{X}$ keeps (on) at $\mathrm{Y}$ (to make $\mathrm{Y}$ frightened/ under pressure)

He'd kept on at her, wanting her to go out with him.

$18 \mathrm{Y}$ is an Experiencer and $\mathrm{X}$ is a Stimulus. 
11. X comes down on $\mathrm{Y}$ (to frighten $\mathrm{Y}$ )

The boss will come down on you like a ton of bricks when he finds out what you've done.

12. X gets on Y's nerves (to irritate $\mathrm{Y}$ )

All this flying around got on my nerves. But then I gave the script to Cathy to get her opinion.

13. X gets under Y's skin (to irritate $\mathrm{Y}$ )

Ignore Justin: don't let him get under your skin.

(27) Psychological ObjExp idiomatic phrases with null/implicit PPs

I. $\mathrm{X}$ draws $\mathrm{Y}$ in (to attract $\mathrm{Y}$ )

Your looks draw me in, but your personality is what makes me stay.

II. $\mathrm{X}$ turns $\mathrm{Y}$ on (to attract $\mathrm{Y}$ )

Her intelligence turns me on.

III. X blows Y's mind (to make Y excited)

This whole business just blows my mind.

IV. X goes down a treat [for $\mathrm{Y}]^{19}$ (to make $\mathrm{Y}$ excited)

Not coffee, that imitation stuff tastes awful, but a cup of tea will go down a treat [for you].

V. $\mathrm{X}$ hits the spot [for $\mathrm{Y}$ ] (to make $\mathrm{Y}$ satisfied because $\mathrm{X}$ is something most required)

That cup of coffee really hit the spot [for you].

VI. X carries $\mathrm{Y}$ away (to fill $\mathrm{Y}$ with emotion / enthusiasm)

I'm self-conscious but let go of that fast as the river of emotion and sensations carries me away.

VII. $\mathrm{X}$ blows $\mathrm{Y}$ away (to surprise or please $\mathrm{Y}$ very much)

The ending will blow you away.

VIII. X bowls Y over (to greatly astonish Y)

You must go hear this poet - you will be bowled over!

IX. $\mathrm{X}$ puts $\mathrm{Y}$ up for sth/ to do sth (to encourage $\mathrm{Y}$ ) And he said, "So I should put her up for adoption."

$\mathrm{X}$. X hits/strikes the right note [on Y] (to have positive effects on $\mathrm{Y}$ )

He saw his remarks had struck the right note - his friend was smiling now.

$\mathrm{XI}$. X raises a dust [at/for $\mathrm{Y}$ ] (to cause a disturbance by something $\mathrm{X}$ does or says)

You may indeed raise a dust [for others] with those terms, and so lengthen our dispute to no purpose.

XII. X kicks up a dust [at/for Y] (to cause a disturbance by something X does or says)

While beginners simply enjoy the ride, advanced boarders kick up the dust [for others] at competitions.

XIII. X raises hell/Cain/the devil/the roof [at/in front of Y] (to cause a great uproar or disturbance) He said he'd raise Cain [for them] if they wouldn't give him a refund.

$\mathrm{XIV}$. $\mathrm{X}$ is/seems a wet blanket [for Y] (to trouble, disturb through complaining)

Oh, Martin! Why do you have to be such a wet blanket [for them]?

XV. X breaks Y's heart (to make Y sad)

Don't break my heart don't make me frown.

XVI. $\quad \mathrm{X}$ eats $\mathrm{Y}$ up (to worry $\mathrm{Y}$, make $\mathrm{Y}$ nervous)

Fred will just eat you up. He is a vicious administrator.

19 The square brackets introduce a word/phrase added by me, not provided in the dictionary, just to make the meaning of the whole unit clear, and to show the position of an Experiencer. The occurrence of an Experiencer in some idiomatic units is not explicit, it seems to be non-overt/empty, although semantically it is obvious that the Experiencer exists, thus it may be overtly realised. 
XVII. X knocks Y for six (to upset $\mathrm{Y}$ very much)

The news of his death knocked me for six.

XVIII. X lets $\mathrm{Y}$ down (to upset $\mathrm{Y}$ very much)

I was counting on John to come, but he let me down.

XIX. X puts Y's nose out of joint (to upset Y)

Brad had his nose put out of joint when he saw that he didn't get top billing on the movie poster.

$\mathrm{XX}$. $\mathrm{X}$ reduces $\mathrm{Y}$ to tears (to make $\mathrm{Y}$ cry/ upset)

I can't remember the number of times he reduced me to tears.

XXI. X cuts $\mathrm{Y}$ up (to upset $\mathrm{Y}$ )

It cuts me up to see you sad. And I wish that I could undo what I've done.

XXII. X gets $\mathrm{Y}$ down (to depress $\mathrm{Y}$ )

When life gets you down What you gonna do?

XXIII. X puts $\mathrm{Y}$ out (to upset $\mathrm{Y}$ )

Did our early arrival put you out?

XXIV. X shakes Y up (to upset/ disturb Y)

The assassination of the President shook me up terribly.

$\mathrm{XXV}$. X puts $\mathrm{Y}$ to shame (to make $\mathrm{Y}$ feel ashamed)

She works so hard that she puts me to shame.

XXVI. X turns Y's brain (to disturb Y mentally)

What a ghastly sight for the poor woman! I wonder it did not turn her brain to look on it.

XXVII. X tells Y where to get off (to make Y frightened)

When he called back a third time, I told him where to get off.

XXVIII. X makes Y's blood boil (to make Y angry)

The thought made her blood boil with rage, and she nearly knocked over a pan of hot bacon grease.

XXIX. X rattles Y's cage (to make Y angry)

'I suppose I rattled your cage a few times in the beginning.' (...) 'You rattled more than my cage.

You rattled my confidence.'

XXX. X makes $\mathrm{Y}$ all hot and bothered (to make $\mathrm{Y}$ angry)

I said softly, hating when he made me all hot and bothered in public.

XXXI. X gets Y's goat (to make $\mathrm{Y}$ angry)

But what gets my goat is how he plays with the shiv [knife] of racism.

XXXII. X acts up [against / in front of Y] (to cause annoyance)

What do you do when your asthma acts up?

XXXIII. $\quad \mathrm{X}$ is not Y's bag (to fill Y with disgust)

Thank you for the invitation, but long-distance cycling just isn't really my bag.

XXXIV. X gets Y's back up (to annoy Y)

That joke really got my boss's back up.

$\mathrm{XXXV}$. $\mathrm{X}$ drives $\mathrm{Y}$ to drink (to cause $\mathrm{Y}$ so much annoyance)

Being a Cubs fan is enough to drive you to drink.

XXXVI. X rubs $\mathrm{Y}$ up the wrong way (to irritate $\mathrm{Y}$ )

My younger sister rubs me the wrong way. I find her so annoying!

XXXVII. X sets / puts Y on Y's ear (to make Y furious)

The presence of the movie star set the whole town on its ear. 


\subsection{The data analysis}

Analysing the data, the following answers to the research questions can be given:

A1. Indeed, there are some VP idiomatic expressions that can be used instead of common psych predicates to express one's mental or/and emotional condition

A2. In total, out of 3,000 tokens, 50 psychological verbal idiomatic expressions with an Object Experiencer have been found and presented in two groups. In the first group, in (26), each of the 13 phraseological items comprises an explicit/lexical preposition preceding an Experiencer. The Experiencer seems to become an emotional or mental location of such states as enthusiasm, excitement, disturbance, annoyance, fear, anger, etc., which appears to be compatible with Landau's (2010) localist approach. Since the Experiencer figures within a PP in a substantial number of cases (nearly one third) out of those 50 idioms collected, it seems to be justified to extend the PP-analysis to those cases in which the preposition is not overtly present, as in (27). The other group with covert/empty preposition includes 37 out of the 50 idiomatic units with an Object Experiencer.

A3. As far as the syntactic status of those ObjExp idiomatic units, (28) presents an overview of the 50 collected phraseological items which represent various syntactic patterns, preserving the main structural schema: $\mathrm{V}+$ (overt/covert) PP. Thus, the idioms having been scrutinised fall into seven distinct types.

\subsubsection{Surface syntax of the distinct patterns of the idiomatic verbal phrases}

(28) Syntactic patterns of psych idiomatic $\mathrm{V}+\mathrm{PP}$ structures, in which an Experiencer is located in $\mathrm{a}(\mathrm{n})$ (overt/covert) PP:
a. Causer/Stimulus X $+\mathrm{V}+$ object $+\mathrm{PP}$ with Experiencer $\mathrm{Y}$ e.g., $\mathrm{X}$ is a slap in the face for $\mathrm{Y}$ (to be upsetting)
( 2 items $\rightarrow 4 \%)$
b. Causer/Stimulus $\mathrm{X}+\mathrm{V}+\mathrm{PP}$ with Experiencer $Y$ as a possessor within the prepositional complement e.g., $\mathrm{X}$ treads on $\mathrm{Y}$ 's toes (to upset $\mathrm{Y}$ )
$(4$ items $\rightarrow 8 \%)$
c. Causer/Stimulus $\mathrm{X}+\mathrm{V}+\mathrm{PP}$ with Experiencer $\mathrm{Y}$
(3 items $\rightarrow 6 \%$ )
e.g., $\mathrm{X}$ turns on $\mathrm{Y}$ (to get $\mathrm{Y}$ engaged, attract $\mathrm{Y}$ )
d. Causer/Stimulus $\mathrm{X}+\mathrm{V}+$ particle of phrasal verb $+\mathrm{PP}$ with Experiencer $\mathrm{Y}$ (5 items $\rightarrow 10 \%)$ e.g., $\mathrm{X}$ bears down on $\mathrm{Y}$ (to scare $\mathrm{Y}$ )
e. Causer/Stimulus $\mathrm{X}+\mathrm{V}+\mathrm{PP}+$ non-overt $\mathrm{PP}$ with Experiencer $\mathrm{Y}$
$(2$ items $\rightarrow 4 \%)$
e.g., $\mathrm{X}$ goes down a treat [for $\mathrm{Y}]$ (to make $\mathrm{Y}$ excited)
f. Causer/Stimulus X $+\mathrm{V}+$ object + empty/null PP with Experiencer $\mathrm{Y} \quad(5$ items $\rightarrow 10 \%)$ e.g., $\mathrm{X}$ hits the spot [with $\mathrm{Y}]$ (to make $\mathrm{Y}$ satisfied)
g. Causer/Stimulus $\mathrm{X}+\mathrm{V}+$ never overt PP with Experiencer $\mathrm{Y} \quad$ (30 items $\rightarrow 60 \%$ )
1. Experiencer $\mathrm{Y}$ followed by a particle of phrasal verb e.g., $\mathrm{X}$ draws $\mathrm{Y}$ in (to attract $\mathrm{Y}$ )
$(12$ items $\rightarrow 24 \%)$
2. Experiencer $\mathrm{Y}$ as a possessor within $\mathrm{DP}$ e.g., X turns Y's brain (to disturb Y mentally)
$(9$ items $\rightarrow 18 \%)$
3. Experiencer $\mathrm{Y}$ followed by a fixed $\mathrm{PP}$
e.g., $\mathrm{X}$ knocks $\mathrm{Y}$ for six (to upset $\mathrm{Y}$ very much)
$(5$ items $\rightarrow 10 \%)$
4. Experiencer $\mathrm{Y}$ followed by a fixed clause/ adverbial e.g., $\mathrm{X}$ drives $\mathrm{Y}$ to drink (to cause $\mathrm{Y}$ so much annoyance)
$(5$ items $\rightarrow 10 \%)$ 
The variety of object arguments, recognised in our analysis, is always richer in languages that have a morphological case. Then, the arguments of a predicate must appear with the appropriate case forms (e.g., nominative, accusative, dative, genitive, etc.) imposed on them by the predicate. The 50 units analysed in this study reveal that the verbal phrases are mostly represented by action verbs ( 45 units $\rightarrow 90 \%$ ), e.g., go, get, turn, keep, bear, come, raise, tread, kick and hit, which are mostly accompanied by a particle as a constituent of a phrasal verb (19 items $\rightarrow 38 \%$, e.g., $\mathrm{X}$ bears down on Y 'to scare Y'), an NP object in front of the PP (7 items $\rightarrow$ $14 \%$, e.g., $\mathrm{X}$ hits the spot [with $\mathrm{Y}$ ] 'to make $\mathrm{Y}$ satisfied'), a VP with the PP (3 items $\rightarrow 6 \%$, e.g., $\mathrm{X}$ turns on $\mathrm{Y}$ (to get $\mathrm{Y}$ engaged, attract $\mathrm{Y}$ ). In 5 units $(\rightarrow 10 \%)$ the verbal phrase consists of a copular 'be', followed either by a NP object (X is a wet blanket), or by a particle typical of phrasal verbs ( $\mathrm{X}$ is on at $\mathrm{Y})$.

According to Landau's (2010) localist approach, the Experiencer designates a mental location, thus it is placed within the structure of a PP. This PP may be headed by a lexical P (as in English obliques) or a null P (as in Latin obliques); nevertheless, both cases are structurally distinct from bare DPs (Landau 2010, pp. 21-22). Our data show that the lexical PP with an Experiencer as an object appears only in 13 (26\%) phraseological units out of the 50, whereas 37 items (74\%) include an Experiencer Y without an overt preposition.

Furthermore, the Experiencer either in the lexical PP or a null PP is represented in most cases by an NP (37 items $\rightarrow 74 \%$ ), but in 13 items $(\rightarrow 26 \%)$ it is hidden in the possessive form of the NP within the PP (e.g., X is music to Y's ears 'to make Y excited'). Besides, for some of the phraseological units under scrutiny ( 7 units $\rightarrow 14 \%$ ) the Experiencer located within a PP is nonovert/empty, since the meaning of the idiom takes the existence of an Experiencer for granted. Finally, within the $\mathrm{V}+\mathrm{PP} /$ non-overt PP fixed structure, 1 phraseological unit $(\rightarrow 2 \%)$ forms a fixed simile/comparison, (X comes down on Y like a ton of bricks 'to reprimand Y severely'), 5 items $(10 \%)$ are tailed by a fixed clause/adverbial (e.g., $\mathrm{X}$ tells $\mathrm{Y}$ where to get off 'to make $\mathrm{Y}$ frightened').

\section{Concluding remarks}

In brief, cross-linguistically and within different languages, psych-verbs are classified similarly to the three-way division offered by Belletti \& Rizzi (1988). Two attempts have been made in this study, i.e. (1) to present some crucial background concerning psych-verbs, with a focus on Landau's (2010) approach; and (2) to investigate the linguistic inventory of verbal idioms in terms of phrases that represent mental or/and emotional condition, while comparing the results to Landau's (2010) localist perspective.

The set of definitions and classifications of psych-verbs, introduced at the very beginning of the analysis became the key for the discussion conducted afterwards. The main concern here was, however, a group of Object Experiencer verbs and the psych-effects they exhibit. In particular, all the properties attributed to ObjExp verbs exist with the stative reading, the typical psych reading, but none of them exists with the agentive one, in which the predicate behaves like a normal transitive agentive predicate. The fundamental thesis of this study has been that Experiencers are locations. In the research section, the V + PP idiomatic expressions, including 
the instances with non-overt/Ø $\psi$ null prepositions, have been examined as regards their psychological connotation.

The results of the study reveal that the phraseological units can be treated as an alternative to traditional psych-verbs (please, worry, frighten, etc.) to express one's emotional or/and mental condition. However, in total, out of 3,000 tokens, there are only 50 psychological verbal idiomatic expressions with an Object Experiencer. The data show that a lexical $\mathrm{P}$ with the Experiencer as an object appears only in 13 (26\%) idiomatic expressions out of the 50. Indeed, these may serve as some evidence for Landau's (2010) theory. Nonetheless, much more idioms, i.e. 37 items (74\%), include an Experiencer preceded with no P. The latter might be treated as exhibiting an oblique Experiencer with a null preposition. However, no relevant syntactic evidence can be found in support the claim that there is a covert $\mathrm{P}$ in this type of phrases. Therefore, the use of psychological idioms and the results obtained in this study do not provide enough evidence in favour of Landau's (2010) theory of Experiencers as mental locations, placed either in a covert or overt PP.

Nevertheless, psych predicates and their idiomatic counterparts invite further investigation, concerning both the source of their unusual behaviour (mainly from the syntactic point of view), and quantitative research (different corpus-based and / or corpus-driven studies).

\section{References}

Arad, M. (1998). Psych-notes. UCL Working Papers in Linguistics 10. London: University College.

Arad, M. (2000). Psych Verbs and the Syntax-Lexicon Interface. Ms., University of Geneva.

Baker, M. C. (1997). Thematic roles and syntactic structure. In L. Haegeman (Ed.), Elements of grammar: Handbook in generative syntax (pp. 73-137). Dordrecht: Kluwer.

Belletti, A., \& Rizzi, L. (1988). Psych-verbs and $\theta$ theory. Natural Language and Linguistic Theory 6, 291-352.

Bouchard, D. (1995). The Semantics of Syntax: A Minimalist Approach to Grammar. Chicago: University of Chicago Press.

COCA (Corpus of Contemporary American English). Available at http://corpus.byu.edu/coca/, last accessed on 25th January 2016.

Doron, E. (2003). Agency and voice: the semantics of the Semitic templates. Natural Language Semantics 11, 1-67.

Dowty, D. R. (1991). Thematic Proto-roles and Argument Selection. Language 67, 547-619.

Emonds, J. (1985). A Unified Theory of Syntactic Categories. Dordrecht: Foris.

Fábregas, A., \& Marín, R. (2015). Deriving individual-level and stage-level psych verbs in Spanish. The Linguistic Review (De Gruyter Mounton) 32(2), 167-215.

Google Books Corpus. Accessed online at: http://googlebooks.byu.edu/x.asp

Guidi, L. G. (2011). Old English psych-verbs and quirky experiencers. York Papers in Linguistics Series 2 (11), 2948.

Grafmiller, J. (2013). The semantics of syntactic choice: An analysis of English emotion verbs. Unpublished PhD thesis, Stanford University.

Grimshaw, J. (1990). Argument structure. Cambridge, MA: MIT Press.

Iwata, S. (1995). The Distinctive Character of Psych-Verbs as Causatives. Linguistic Analysis 1-2, 95-120.

Jackendoff, R. (1990). Semantic Structures. Cambridge, MA: MIT Press.

Johnson, K. (1992). Scope and Binding Theory: Comments on Zubizarreta. In T. Stowell \& E. Wehrli (Eds.), Syntax and Semantics, Vol. 26: Syntax and the Lexicon (pp. 259-275). San Diego: Academic Press Inc.

Keysar, B., \& Bly, B. M. (1999). Swimming against the current: do idioms reflect conceptual structure? Journal of Pragmatics 31(12), 1559-1578. 
Klein, K., \& Kutscher, S. (2005). Lexical Economy and Case Selection of Psych-Verbs in German. Köln/Bochum: Manuskript. Unpublished.

Lakoff, G. (1987). Women, Fire, and Dangerous Things. Chicago, IL: University of Chicago Press.

Lakoff, G., \& Johnson, M. (1980a). Metaphors We Live By. Chicago, IL: University of Chicago Press.

Lakoff, G., \& Johnson, M. (1980b). The metaphorical structure of the human conceptual system. Cognitive Science 4, 195-208.

Landau, I. (2010). The Locative Syntax of Experiencers (Linguistic Inquiry Monographs 53: $\mathrm{x}+165)$. Cambridge, MA: MIT Press.

Marín, R., \& McNally, L. (2011). Inchoativity, change of state, and telicity: Evidence from Spanish reflexive psychological verbs. Natural Language and Linguistic Theory 29, 467-502.

McCloskey, J., \& Sells, P. (1988). Control and A-Chains in Modern Irish. Natural Language and Linguistic Theory 6, 143-189.

O’Dell, F., \& McCarthy, M. (2010). English Idioms in Use Advanced. Cambridge: Cambridge University Press.

Perlmutter, D. M., \& Postal, P. (1984). The 1-Advancement Exclusiveness Law. In D. M. Perlmutter \& C. Rosen (Eds.), Studies in Relational Grammar 2 (pp. 81-125). Chicago: University of Chicago Press.

Pesetsky, D. (1995). Zero Syntax: Experiencers and Cascades. Cambridge, MA: MIT Press.

Pylkkänen, L. (2000). On Stativity and Causation. In C. L. Tenny \& J. Pustejovsky (Eds.), Events as Grammatical Objects: The Converging Perspective of Lexical Semantics and Syntax (pp. 417-444). Stanford CA: CSLI Publications.

Reinhart, T. (2002). The Theta System - An overview. Theoretical Linguistics 28, 229-290.

Roberts, I. (1991). NP-movement, Crossover and Chain Formation. In H. Haider \& K. Netter (Eds.), Representation and Derivation in the Theory of Grammar (pp. 17-52). Dordrecht: Kluwer Academic Publishers.

Seidl, J., \& McMordie, W. (1978). English Idioms and How to Use Them (Fourth Ed.), Oxford: Oxford University Press.

Speas, M. (1990). Comments on Papers by James Gair, Yamura Kachru and K.P. and Tara Mohanan. In M. K. Verma \& K. P. Mohanan (Eds.), Experiencer Subjects in South Asian Languages (pp. 77-83). Stanford CA: CSLI Publications.

Stowell, T. (1986). Psych-Movement in the Mapping Between D Structure and LF. Paper presented at GLOW 9. Tenny, C. (1998). Psych Verbs and Verbal Passives in Pittsburghese. Linguistics 36, 591-597.

van Voorst, J. (1992). The Aspectual Semantics of Psychological Verbs. Linguistics and Philosophy 15(1), 65-92.

Verhoeven, E. (2010). Agentivity and stativity in experiencer verbs: Implications for a typology of verb classes. Linguistic Typology 14, 213-251.

Wielki multimedialny słownik angielsko-polski i polsko-angielski. [Great Multimedia English-Polish and PolishEnglish Dictionary]. 2005. Oxford: PWN-Oxford. 